\title{
Surface Quality Analysis of Friction Stir Welded Joints by Using Fourier Transformation and Local Binary Patterns Algorithms
}

\author{
Akshansh Mishra ${ }^{1}$ (D) \\ ${ }^{1}$ Politecnico Di Milano, Department of Mechanical Engineering, Milan, Italy.
}

How to cite: Mishra A. Surface quality analysis of friction stir welded joints by using fourier transformation and local binary patterns algorithms. Soldagem \& Inspeção. 2019;25:e2527. https://doi.org/10.1590/0104-9224/SI25.27

\begin{abstract}
Friction Stir Welding process is an advanced solid-state joining process which finds application in various industries like automobiles, manufacturing, aerospace and railway firms. Input parameters like tool rotational speed, welding speed, axial force and tilt angle govern the quality of Friction Stir Welded joint. Improper selection of these parameters further leads to fabrication of the joint of bad quality resulting groove edges, flash formation and various other surface defects. In the present work, a texture based analytic machine learning algorithm known as Local Binary Pattern (LBP) and Fourier transformation algorithm are used for the extraction of texture features of the Friction Stir Welded joints which are welded at a different rotational speed. It was observed that LBP algorithm can accurately detect any irregularities present on the surface of Friction Stir Welded joint and Fourier transformation method can detect the groovy edges present on the Friction Stir Welded joint. In the case study, an image based defect recognition system by using Fourier transformation method is constructed. Five types of filters i.e. Ideal Filter, Butterworth Filter, Low pass Filter, Gaussian Filter and High Pass Filter were used. The results showed that the high pass filter has more capability to detect the edges in comparison to other four filters. It was also observed that Ideal filter has a lot of distortions when compared to the Gaussian Filter and Butterworth Filter.
\end{abstract}

Key-words: Friction stir welding; Local binary pattern; Fourier transformation; Machine vision.

\section{Introduction}

Machine vision is a category of an artificial intelligence method in which majority of success depends on that how we interpret the images and further utilize to a significant degree that utilizes supervised, unsupervised and reinforcement learning [1-3]. Image processed by computers is totally different from the image processed by human eyes as shown in the Figure 1. It is clearly observed that the computer perceives an array of pixels instead of an image. For any type of analysis, machine vision can be thought of as the method which inculcates the development of the algorithms and theories for the extraction of the particular features from the given image [4-7].

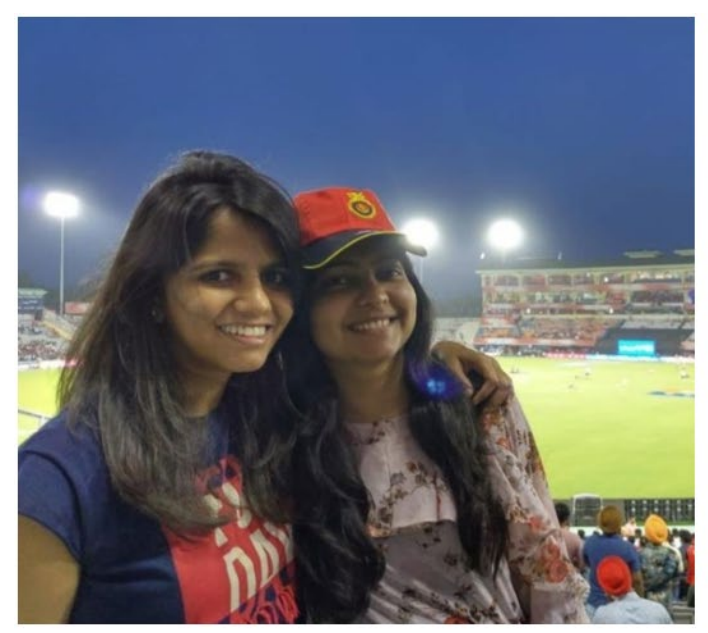

What human eyes see

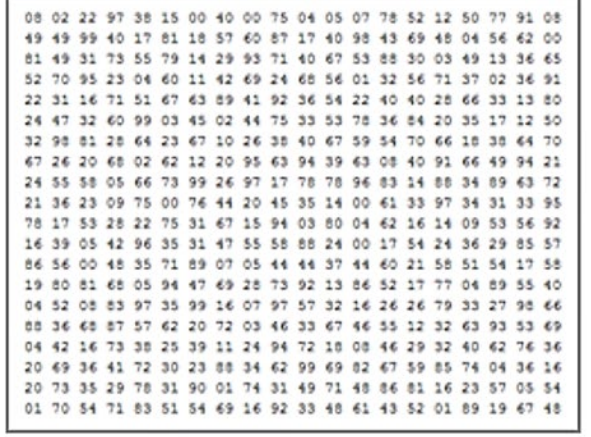

What computer sees

Figure 1. Image processed by human eyes and by a computer system. 
The basic structure of machine vision system can be classified into three stages as illustrated in Figure 2. In the first stage, for capturing the particular image, image acquisition sensors are selected in order to capture clear and best quality images. In the second stage, image segmentation process is carried out. The main purpose of the segmentation process is to separate useful piece information from rest of the image background. In the third stage, image analysis is done for the recognition of the desired features we want as a result.

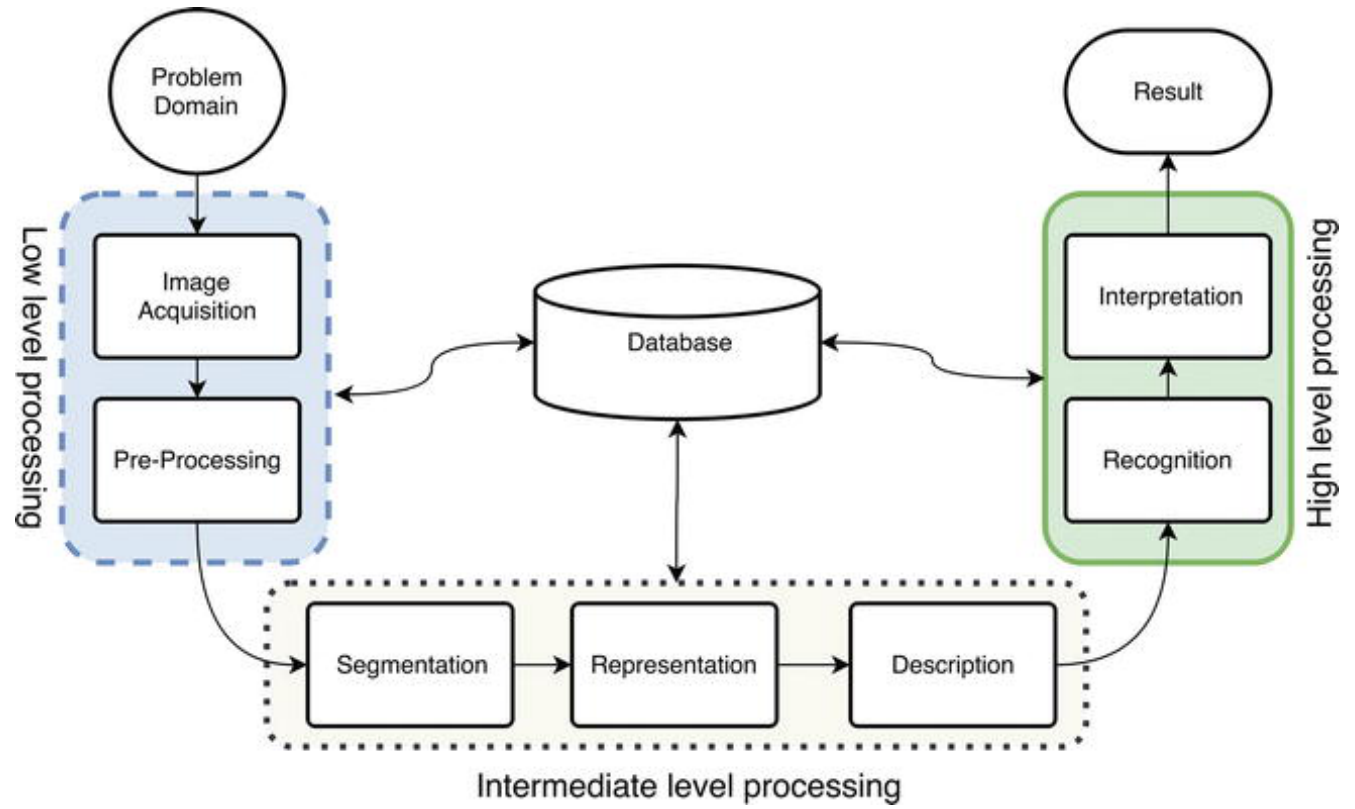

Figure 2. Schematic representation of the working of Machine Vision System [8].

Friction Stir Welding is a solid state joining process which was developed by The Welding Institute (TWI) mainly for joining the light-weight materials like aluminium and magnesium alloys [9-11]. The Friction Stir weldability of aluminium alloys is compared to other conventional fusion welding process. Friction Stir Welding process results high quality welds but the welding performance mainly depends on the proper selection of various input parameters like pin temperature, tool rotational speed, feed rate, welding speed, temperature distribution, rotating tool torque, applied downward forging force on tool shoulder etc. The working mechanism of the Friction Stir Welding process is shown in the Figure 3.

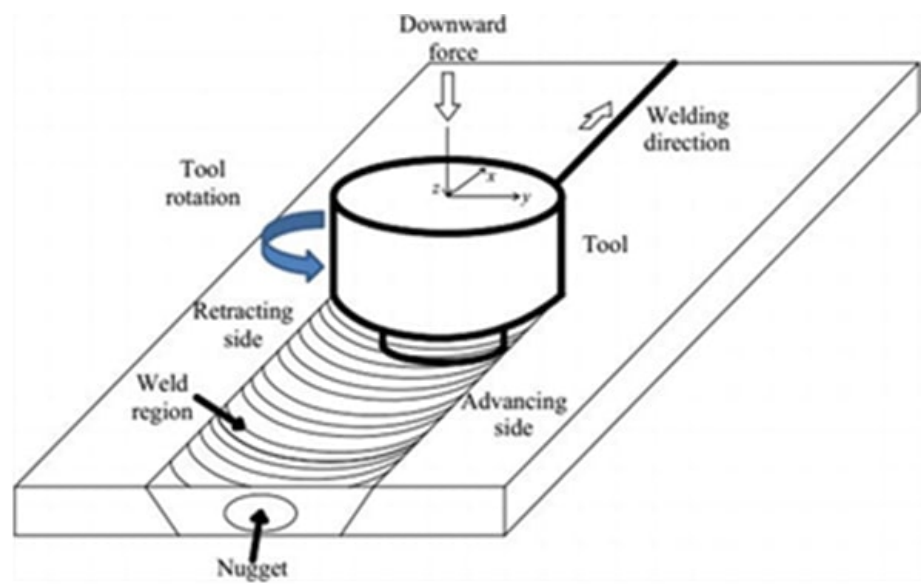

Figure 3. Mechanism of Friction Stir Welding process [11].

The main beauty of the Friction Stir Welding process is that it uses non-consumable metallic tool which is harder than the base material to be joined [12]. The tool consists of a shoulder and pin as shown in the Figure 4b). The tool is plunged inside the base material by applying a downward force. The Friction Stir Welding tool possesses two types of speed i.e. Rotational speed and Traverse speed in the welding direction. Due to the rotation of the rotating tool there is a generation of friction between the work piece and the rotating tool which results in plastic deformation the work piece as shown in the Figure 4c). 
Due to the generated localized heat, the work piece get soften around the probe or pin region which results in the movement of soften or plasticized material from the front part of the probe to the back part of the probe. The welded joint is formed by deforming the material at temperatures below the melting point of parent material [14]. At a very cold welding conditions defects such as void formation and non-bonding can occur while at very hot welding condition issues such as degradation of the strength of the joint can occur as well as there is a formation of collapsible nugget within the stir zone occurs [15].

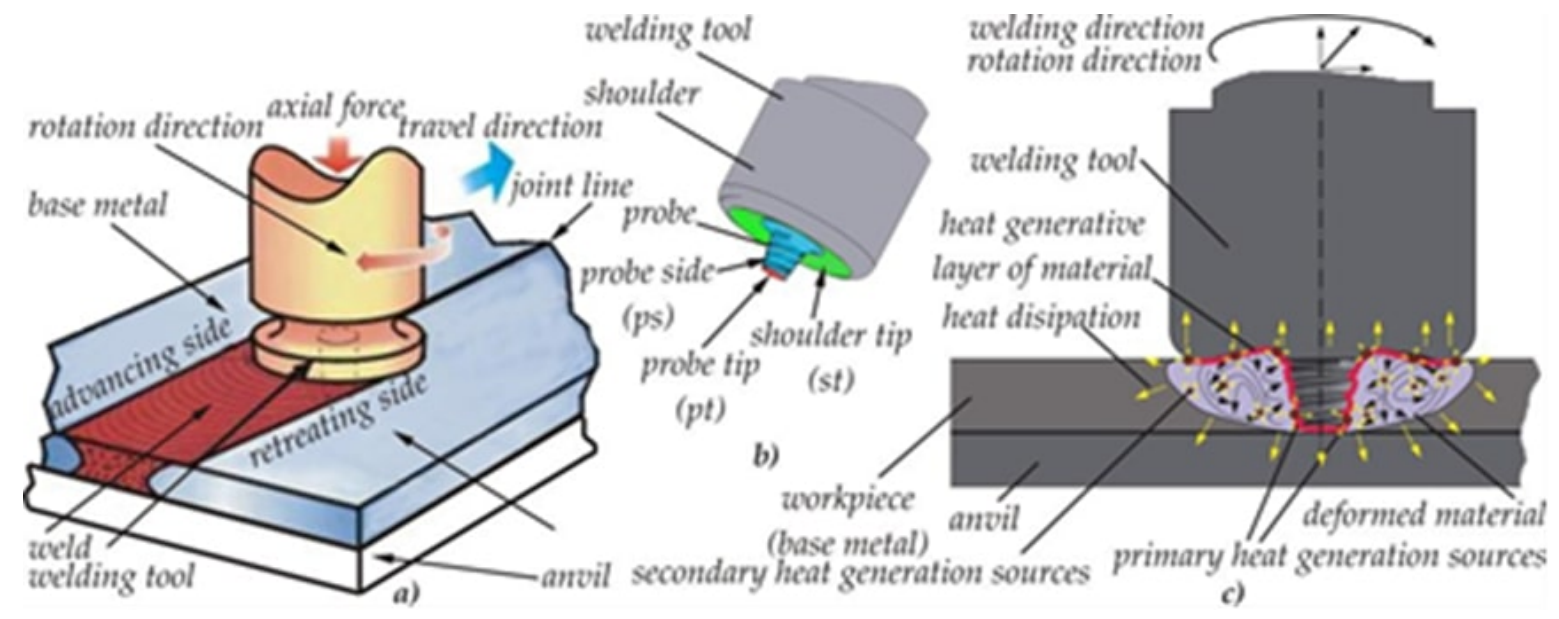

Figure 4. (a) Friction Stir Welding Setup; (b) Tool Nomenclature; (c) Heat generation and plastic deformation in FSW process [13].

In the present work, two machine learning algorithms called Local Binary Pattern (LBP) and Fourier Transformation algorithm have been developed for evaluating the surface defects like lack of penetration, flash formation and groovy edges detection in dissimilar Friction Stir Welded Ultrafine Grained 1050 and 6061-T6 Aluminum Alloys.

\section{Experimental Procedure}

Friction Stir Welding was carried out on $2 \mathrm{~mm}$ thick plate of commercial AA 6061-T6 and Ultrafine grained 1050 aluminium alloy plates [16]. The material used for Friction Stir Welding tool was $\mathrm{H} 13$ tool steel whose shoulder geometry was concave shaped. During welding operation, constant axial load of $8000 \mathrm{kN}$ was applied at a constant rotational speed of $800 \mathrm{rpm}$ and varying traverse speed of $400,600,800,1000 \mathrm{~mm} / \mathrm{min}$. Figure 5a shows the dissimilar Friction Stir Welded joint obtained at tool rotational speed of $800 \mathrm{rpm}$ and $600 \mathrm{~mm} / \mathrm{min}$ while Figure $5 \mathrm{~b}$ shows the dissimilar Friction Stir Welded joint obtained at tool rotational speed of $800 \mathrm{rpm}$ and tool traverse speed of $800 \mathrm{~mm} / \mathrm{min}$. Similarly, Figure 6a shows the dissimilar Friction Stir Welded joint obtained at the tool rotational speed of $800 \mathrm{rpm}$ and tool traverse speed of $400 \mathrm{~mm} / \mathrm{min}$, Figure $6 \mathrm{~b}$ shows the joint obtained at the tool rotational speed of $800 \mathrm{rpm}$ and tool traverse speed of $600 \mathrm{~mm} / \mathrm{min}$, Figure $6 \mathrm{c}$ shows the joint obtained at the tool rotational speed of $800 \mathrm{rpm}$ and tool traverse speed of $800 \mathrm{~mm} / \mathrm{min}$, Figure $6 \mathrm{~d}$ shows the joint obtained at the tool rotational speed of $800 \mathrm{rpm}$ and tool traverse speed of $1000 \mathrm{~mm} / \mathrm{min}$.
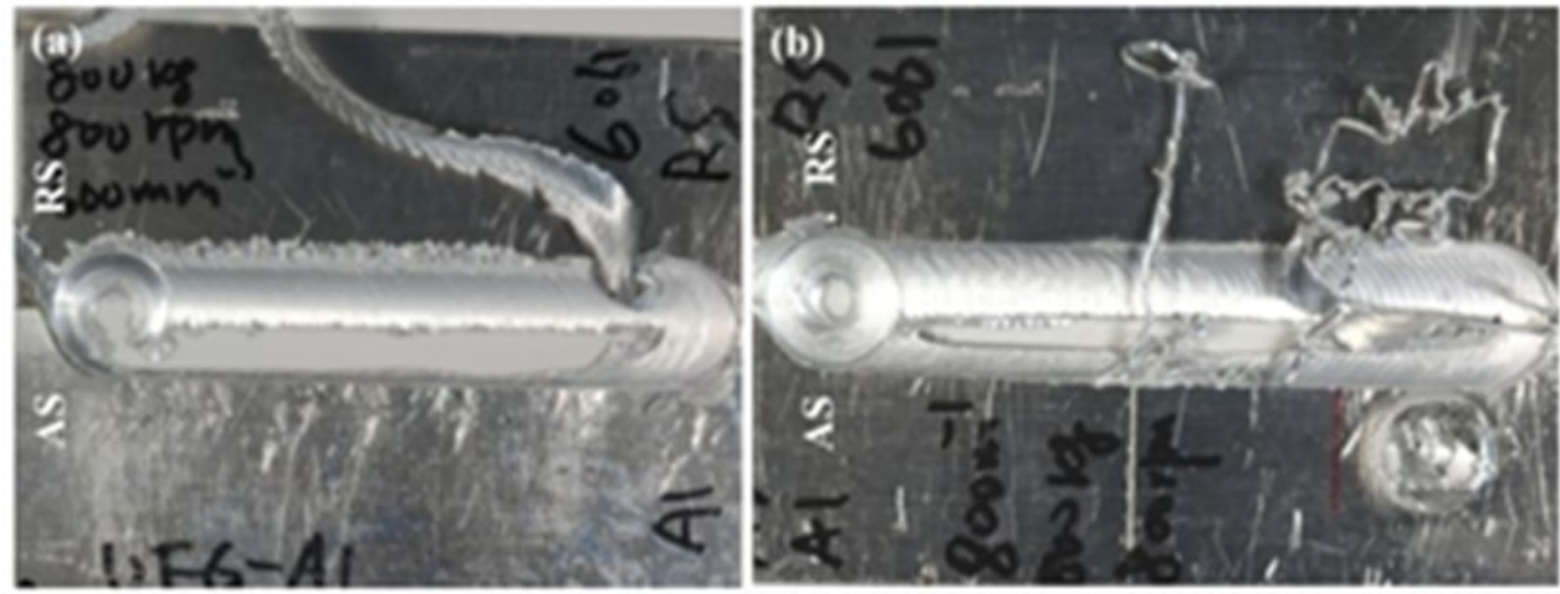

Figure 5. Friction Stir Welded joints obtained at a constant tool rotational speed of $800 \mathrm{rpm}$ and tool traverse speeds of $600 \mathrm{~mm} / \mathrm{min}$ and $800 \mathrm{~mm} / \mathrm{min}$ (AS- Advancing Side, RS- Retreating Side). 

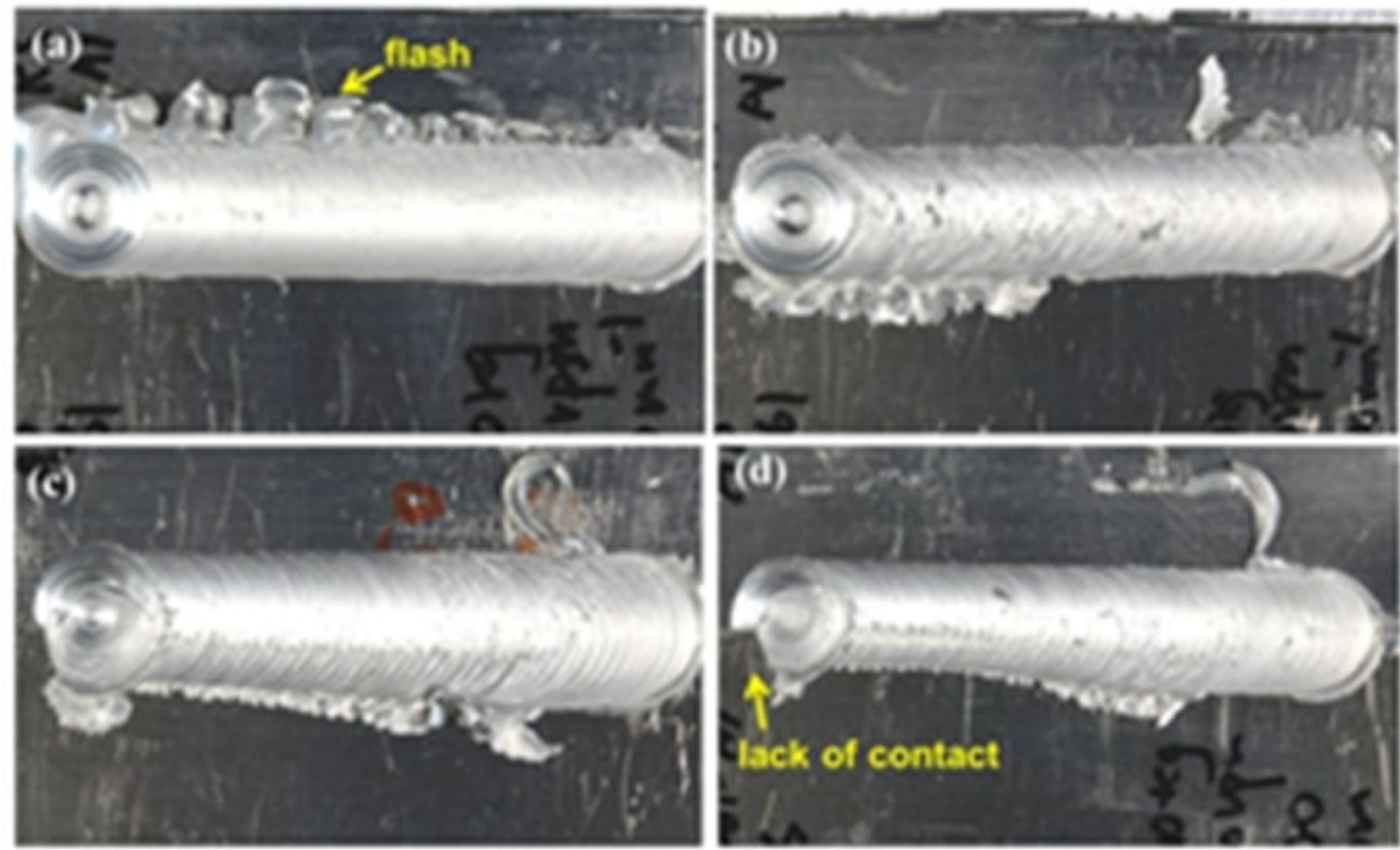

Figure 6. Friction Stir Welded joints obtained at a constant rotational speed of $800 \mathrm{rpm}$ and varying traverse speeds of a) 400 , b) 600 , c) 800 d) $1000 \mathrm{~mm} / \mathrm{min}$.

\subsection{Constructing Local Binary Pattern (LBP) algorithm}

Local Binary Pattern is an important image texture analysis machine vision algorithm which is tolerant against any type of illumination changes in a real time application [17]. Local Binary Pattern creates a grey value difference between the neighbourhood pixels and the centre pixel in the sampling area. In a rectangular neighbourhood with size of $3 \times 3$, Local Binary Pattern is defined. Firstly, conversion of the colour image into grey scale image is done with grey scale value of $0 \sim 255$. As a sampling point, pixels of the rectangular area are used. $f_{0}$ is the grey value of the centre pixel and $f_{1}, f_{2}, f_{3}, \ldots \ldots . . . f_{8}$ are the grey scale values of the 8 pixels around it. The corresponding position is encoded as 1 when $f_{i} \geq f_{0}$. The corresponding position is encoded as 0 when $f_{i}<f_{0}$ as shown in the Figure 7 .

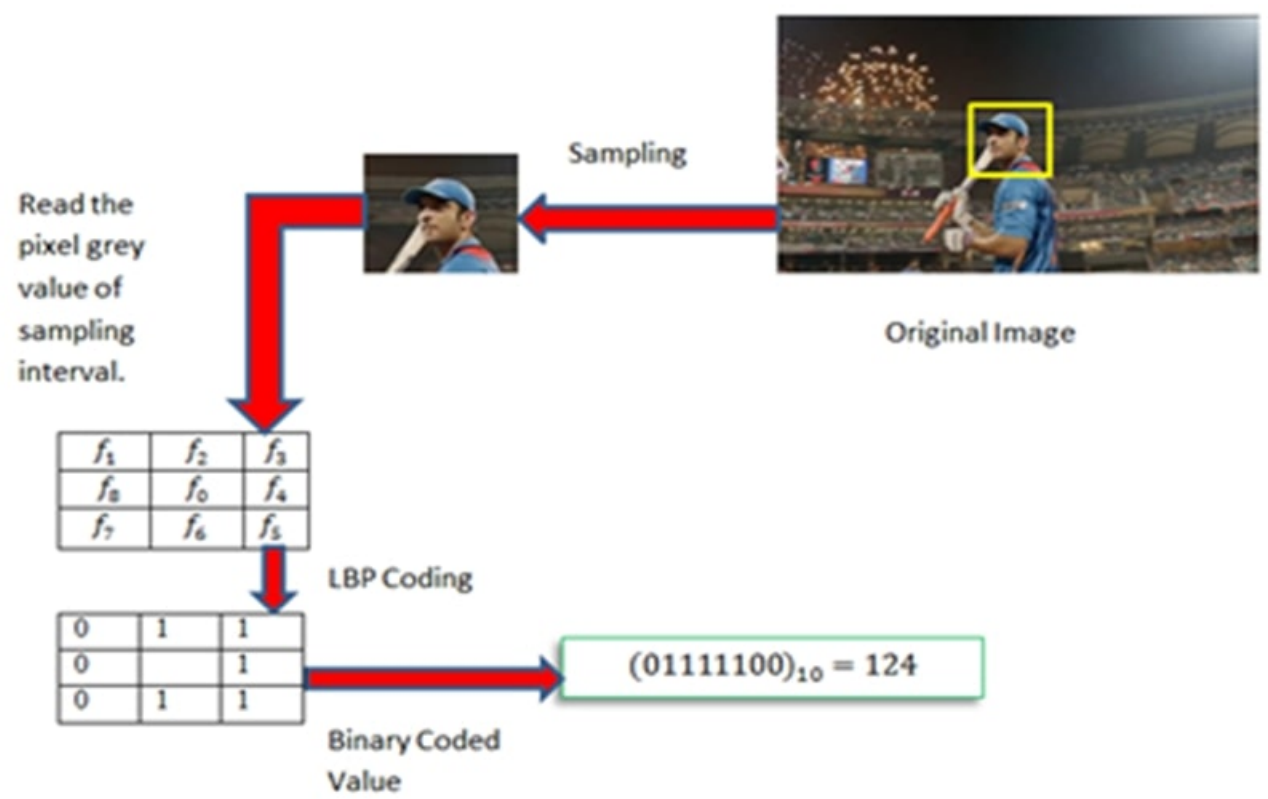

Figure 7. Schematic diagram representing the working of Local Binary Operator. 
Equation 1 describes the coding formula for Local Binary Pattern algorithm.

$\operatorname{LBP}(C)=\sum_{i=1}^{8} S\left(f_{i}, f_{0}\right) \cdot 2^{i-1}$

$S\left(f_{i}, f_{0}\right)=\left\{\begin{array}{l}1, f_{i}-f_{0} \geq 0 \\ 0, f_{i}-f_{0}<0\end{array}\right.$

The obtained images were cropped and were subjected to various operations as shown in the Figure 8 . The Python programming language is used for constructing and simulating the algorithm on Google Colaboratory platform.

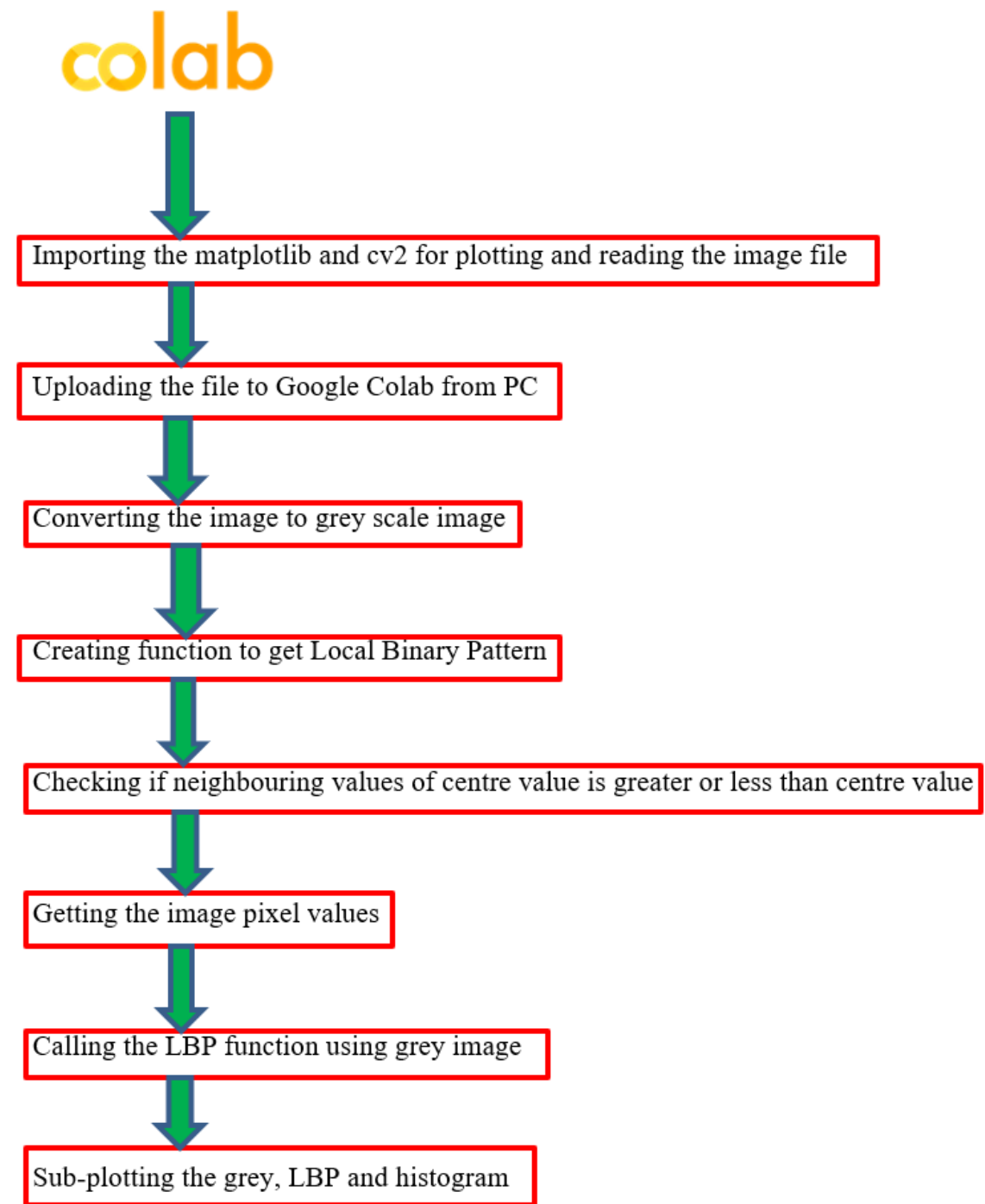

Figure 8. Steps taken for obtaining the grey image, LBP and histogram of the Friction Stir Welded joint.

\subsection{Constructing the Fourier transformation algorithm}

If a function $f(x)$ is defined on $[c, c+2 l]$ or $(c, c+2 l)$ of length ' $2 l$ ', is a periodic function with arbitrary period ' $2 l^{\prime}$ then the fourier series of $f(x)$ is Equation 2 [18]:

$f(x)=\frac{a_{0}}{2}+\sum_{n=1}^{\infty} a_{n} \cos \left(\frac{n \pi x}{l}\right)+\sum_{n=1}^{\infty} b_{n} \sin \left(\frac{n \pi x}{l}\right)$

where, $a_{0}=\frac{1}{l} \int_{c}^{c+2 l} f(x) \cdot d x$ 


$$
\begin{aligned}
& a_{n}=\frac{1}{l} \int_{c}^{c+2 l} f(x) \cos \left(\frac{n \pi x}{l}\right) \cdot d x \\
& b_{n=} \frac{1}{l} \int_{c}^{c+2 l} f(x) \sin \left(\frac{n \pi x}{l}\right) \cdot d x
\end{aligned}
$$

The process flow chart for subjecting the image to fourier transformation is shown in the Figure 9.

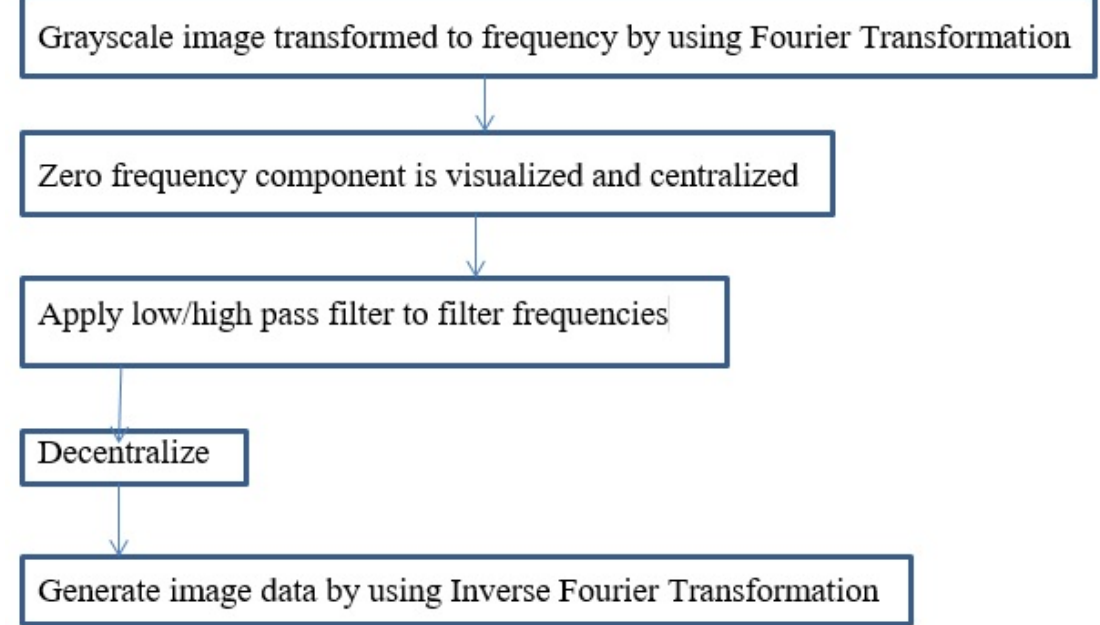

Figure 9. Applying Fourier Transformation to the given image.

\section{Results and Discussions}

The grey images, Local Binary Patterns and histograms of the Friction Stir Welded were obtained as shown in the Figures 10-13. Local Binary Pattern can easily display the non-homogeneous nature of the image. So, various surface defects like flash formation, groovy edges and lack of contact present in Friction Stir Welded joints can be easily detected by implementing Local Binary Patterns. From Figure 10 and Figure 11 it is observed that when the 6061-T6 plate is on retreating side while ultrafine grained 1050 aluminium plate is on advancing side there is a lot of non-homogenity in the LBP converted image with few peak points in histogram. This non-homogenous nature represents improper mixing of both alloy materials. From Figure 12 and Figure 13 it is observed that when the ultrafine grained 1050 aluminium plate is on retreating side and 6061-T6 plate is on advancing side the LBP converted images show more homogenous nature than Figure 10 and Figure 11 and also more peak values are observed in histograms comparison to the histograms of Figure 10 and Figure 11.
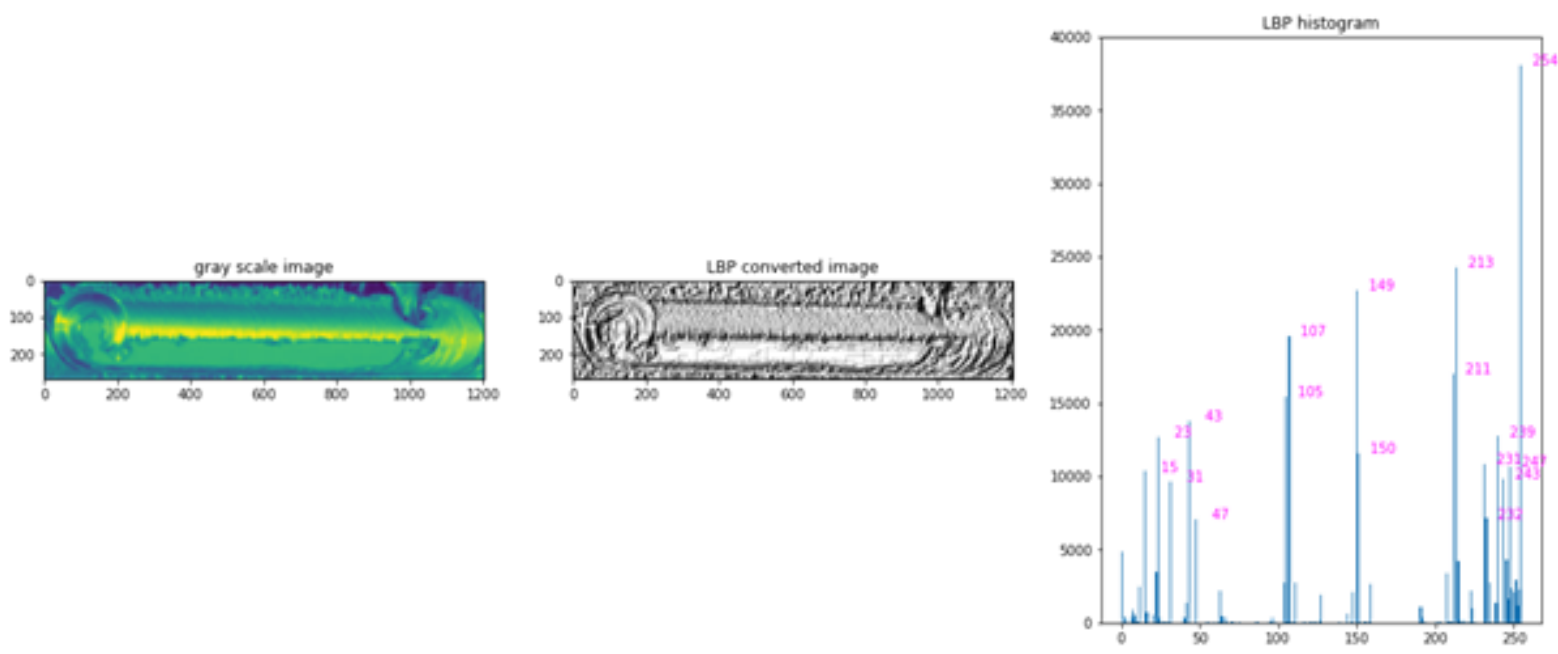

Figure 10. Grey scale image, LBP Converted image and Histogram of Friction Stir Welded joint (6061-T6 on retreating side) obtained at the tool rotational speed of $800 \mathrm{rpm}$ and tool traverse speed of $600 \mathrm{~mm} / \mathrm{min}$. 

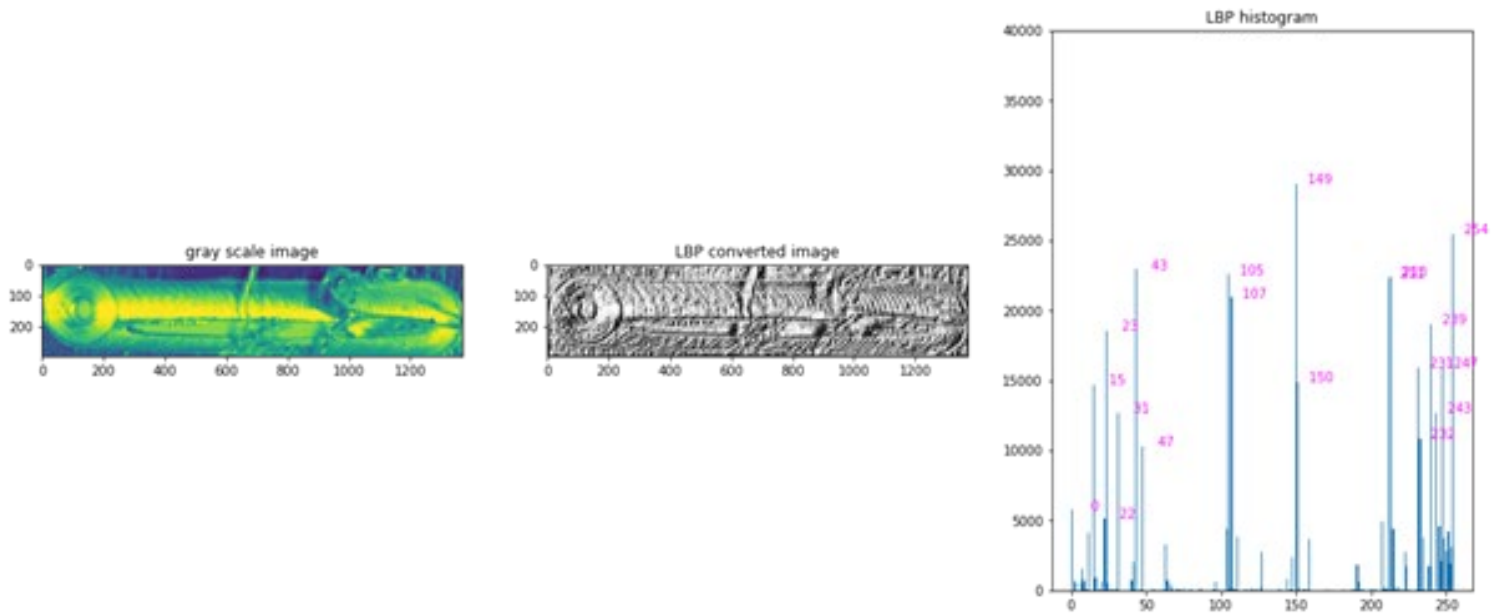

Figure 11. Grey scale image, LBP Converted image and Histogram of Friction Stir Welded joint (6061-T6 on retreating side) obtained at the tool rotational speed of $800 \mathrm{rpm}$ and tool traverse speed of $800 \mathrm{~mm} / \mathrm{min}$.
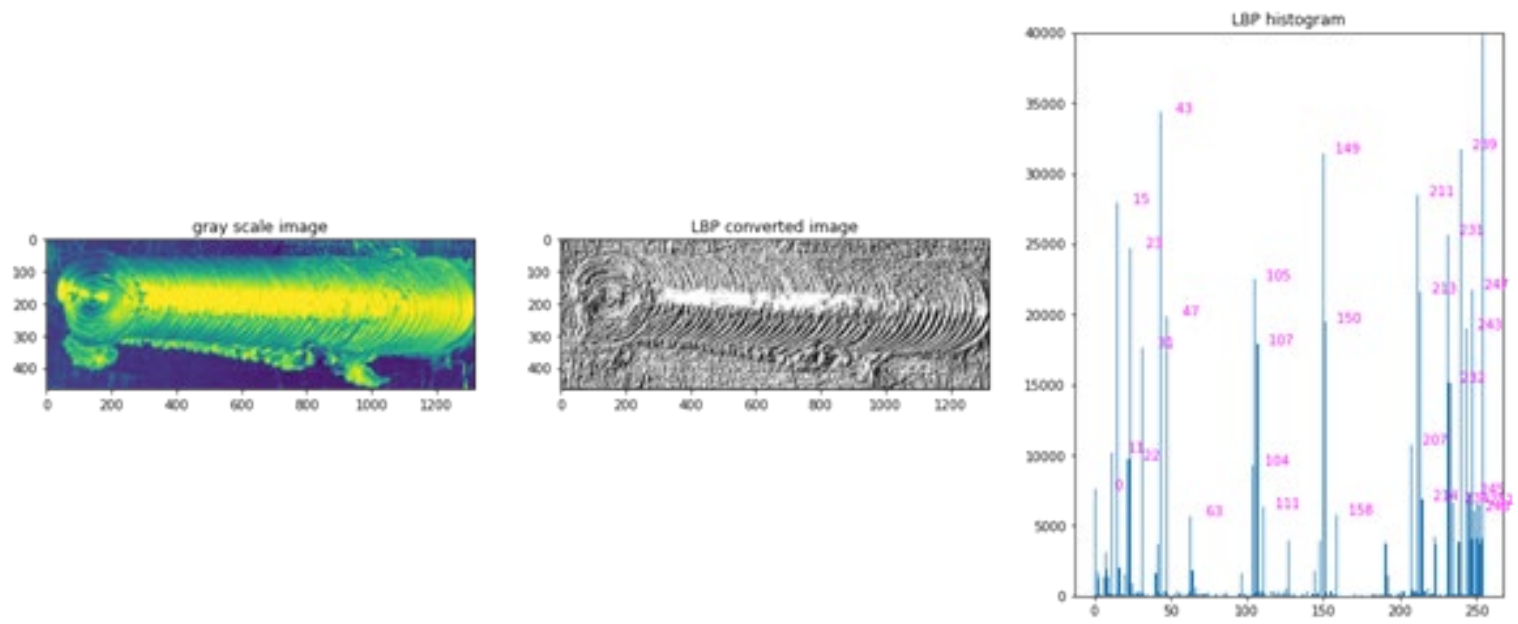

Figure 12. Grey scale image, LBP Converted image and Histogram of Friction Stir Welded joint (6061-T6 on advancing side) obtained at the tool rotational speed of $800 \mathrm{rpm}$ and tool traverse speed of $800 \mathrm{~mm} / \mathrm{min}$.
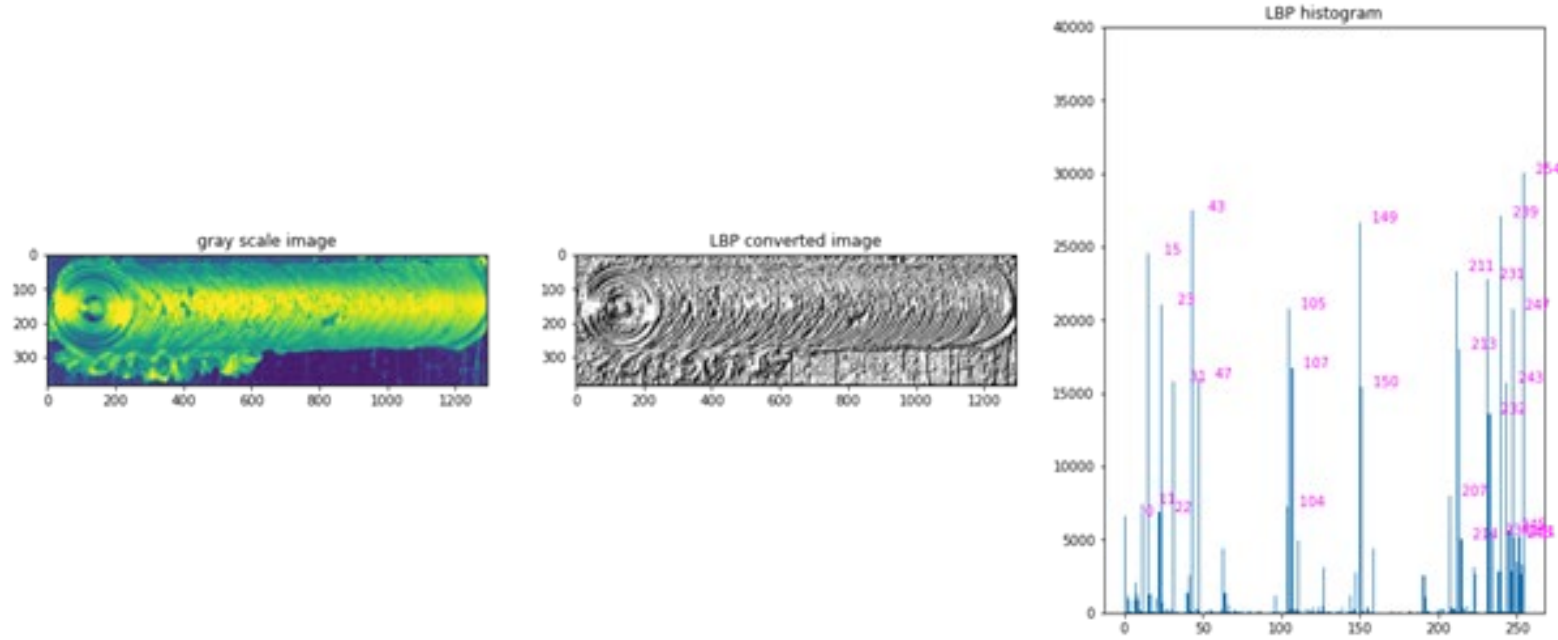

Figure 13. Grey scale image, LBP Converted image and Histogram of Friction Stir Welded joint (6061-T6 on advancing side) obtained at the tool rotational speed of $800 \mathrm{rpm}$ and tool traverse speed of $600 \mathrm{~mm} / \mathrm{min}$. 
Image pixels are discontinuous in nature, so digital images are considered as a discrete. In the research study, Fast Fourier Transformation (FFT) is used instead of Discrete Fourier Transformation (DFT) because the latter is too slow for the image processing task. Figure 14 shows the subjection of the Fourier Transformation to the given friction stir welded joint image.
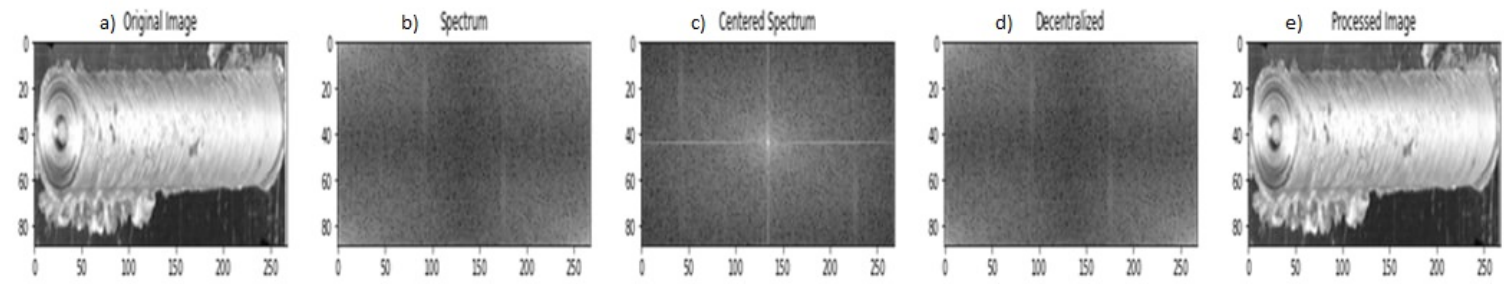

Figure 14. Image subjected to Fourier Transformation. (a) Original Image; (b) Fast Fourier Transform visual output; (c) Centralized; (d) Decentralized; (e) Inverse Fast Fourier Transformation (from left).

The output obtained from Fast Fourier Transformation is very difficult to visualize because they consist of complex numbers array. So the result is transformed into two dimensional spaces. Spectrum and phase angle are two methods to visualize the result of Fast Fourier Transformation as shown in the Figure 15. From the Figure 15a it is observed that on the four corners there are some symmetric patterns which can be translated to the center of the image in the upcoming step. Low frequencies are represented in the corner of spectrum image while high power frequency is represented in the white area of the spectrum image.
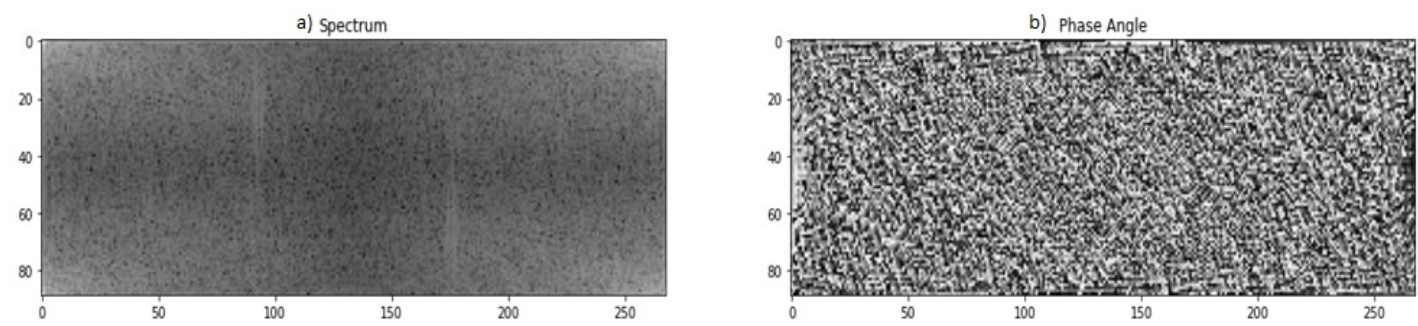

Figure 15. (a) Spectrum; (b) Phase angle (from left).

From Figure 15b it is difficult to extract any distinguishing patterns. Shape characteristics are an essential feature of the image which is preserved by the phase. In order to implement various filters, the zero frequency component was shifted to the center of spectrum. Figure 16 represents the implementation of the low pass filter to the obtained spectrum.

a) Sectum

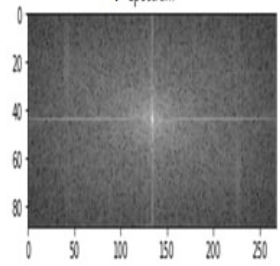

b) Lou Pass fitter

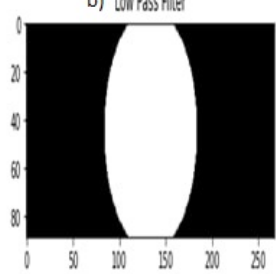

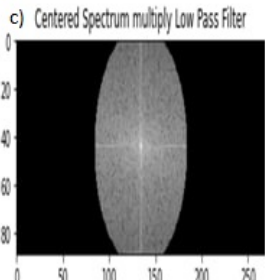

d) Decentralze

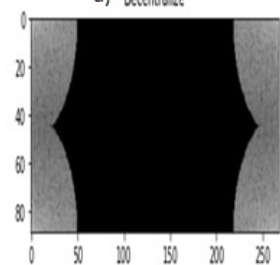

e) Processed Imaje

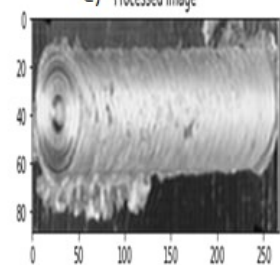

Figure 16. Low pass filter applied to the spectrum.

Low frequencies are allowed to pass through the low pass filters. Low pass filter is useful for removing the noises in the images as noises are high frequencies contents. Figure 17 represents the implementation of the high pass filter to the obtained spectrum.
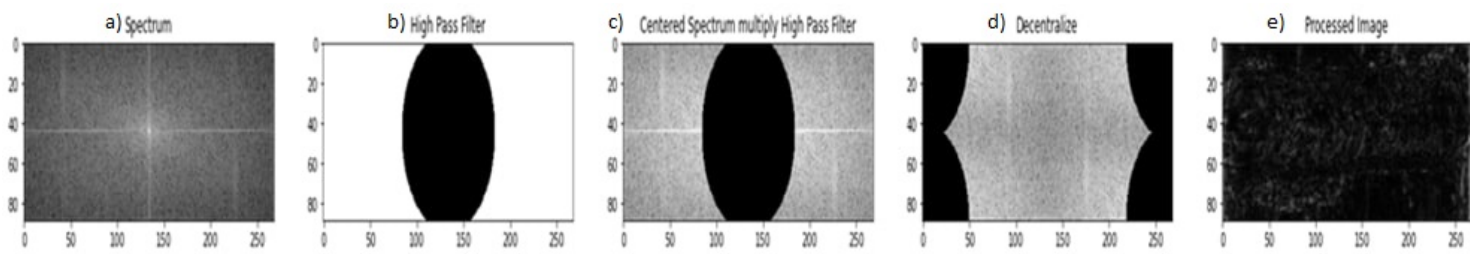

Figure 17.Spectrum subjected to High Pass Filter. 
High frequencies are passed though high pass filter. Pixels values which change drastically represent high frequencies. Edges in the given image are captured by using the high pass filters as shown in the Figure 17 . High pass filters can easily recognize any change in a given image. Equation 3 represents the formula of ideal low pass filter.

$H(u, v)= \begin{cases}1 & \text { if } D(u, v) \leq D_{0} \\ 0 & \text { if } D(u, v)>D_{0}\end{cases}$

In the above equation, $D_{0}$ is a some positive constant and $D(u, v)$ is the distance between the center of the frequency triangle and a point $(u, v)$ in a frequency domain as shown in Figure 18.
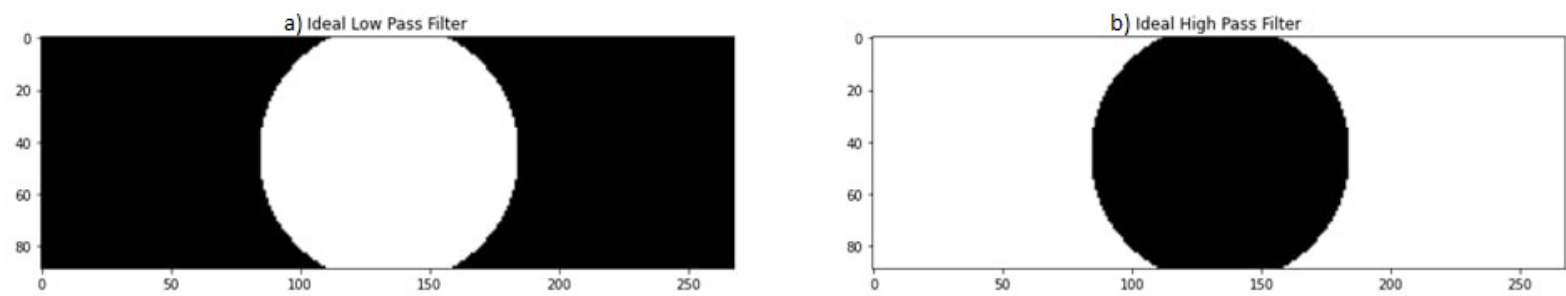

Figure 18. (a) Low pass filter with positive constant $=50$; (b) High pass filter with positive constant $=50$.

Equation 4 represents the formula for ideal high pass filter.

$H(u, v)= \begin{cases}0 & \text { if } D(u, v) \leq D_{0} \\ 1 & \text { if } D(u, v)>D_{0}\end{cases}$

Clear cut off can be achieved between filtered and passed frequencies by using Butterworth filter which is totally different from ideal pass filter. Equation 5 and Equation 6 represents the formula for Butterworth low pass and Butterworth high pass filter respectively. It is also observed in the both equations that a new parameter ' $n$ ' is introduced in the given function whose manipulation affects the clearness of the cut off between the filtered and the passed frequencies as shown in the Figures 19 and 20.

$$
\begin{aligned}
& H(u, v)=\frac{1}{1+\left[D(u, v) / D_{0}\right]^{2 n}} \\
& H(u, v)=\frac{1}{1+\left[D_{0} / D(u, v)\right]^{2 n}}
\end{aligned}
$$
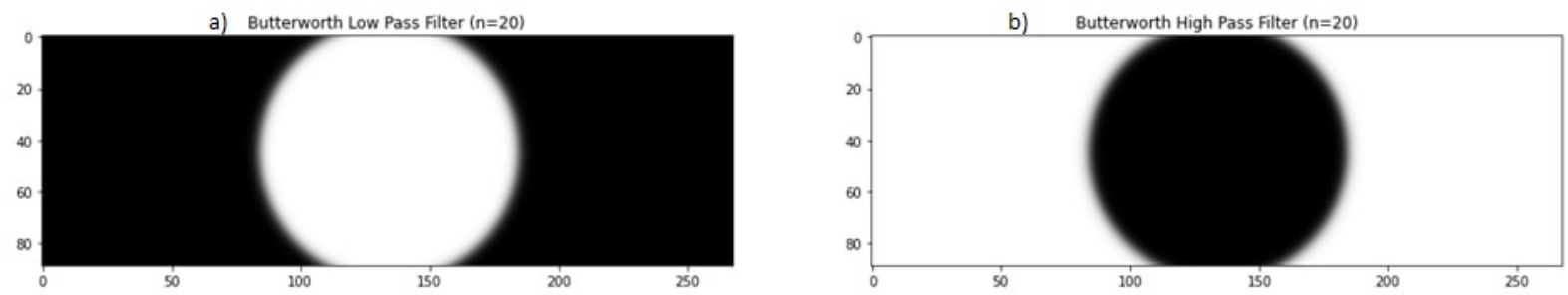

Figure 19. (a) Butterworth low pass filter with positive constant $=50$ and $n=20$; (b) Butterworth high pass filter with positive constant $=50$ and $\mathrm{n}=20$ (from left).
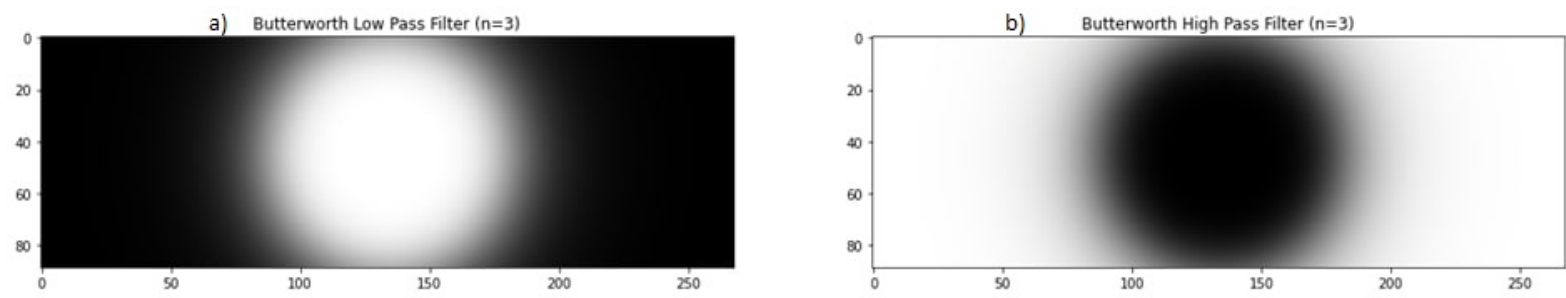

Figure 20. (a) Butterworth low pass filter with $n=3$; (b) Butterworth high pass filter with $n=3$ (from left). 
On the other hand, in comparison to the Butterworth filter, Gaussian filter provides smoother cut off. Equation 7 and Equation 8 represents the formulas for Gaussian Low pass and Gaussian High pass filter respectively.

$$
\begin{aligned}
& H(u, v)=e^{-D^{2}(u, v) / 2 D_{0}^{2}} \\
& H(u, v)=1-e^{-D^{2}(u, v) / 2 D_{0}^{2}}
\end{aligned}
$$

Gaussian filter results smoother processed images because the cut off between filtered and passed frequencies are blurry in nature which is shown in the Figure 21.
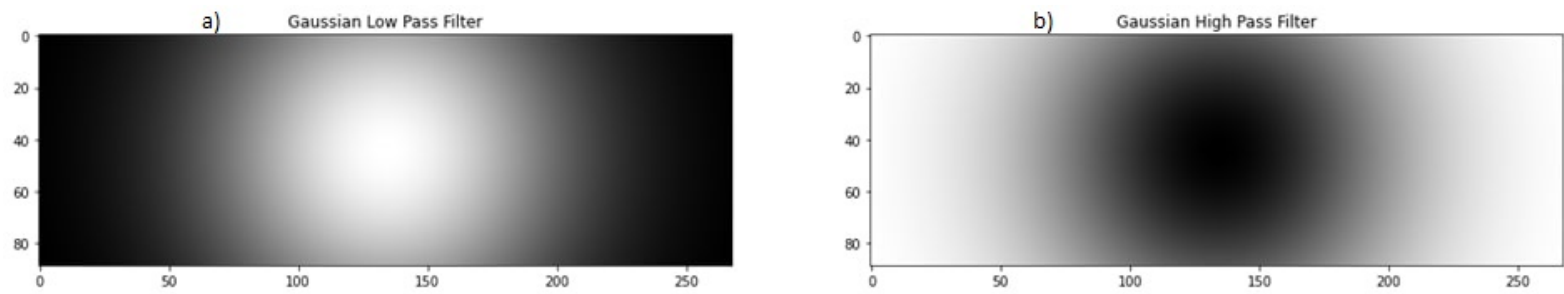

Figure 21. (a) Gaussian low pass filter with positive constant=50; (b) Gaussian high pass filter with positive constant=50 (from left).

Figure 22 shows that in comparison to the other filters, High pass filter results better edge detection accuracy in the friction stir welded joint image.
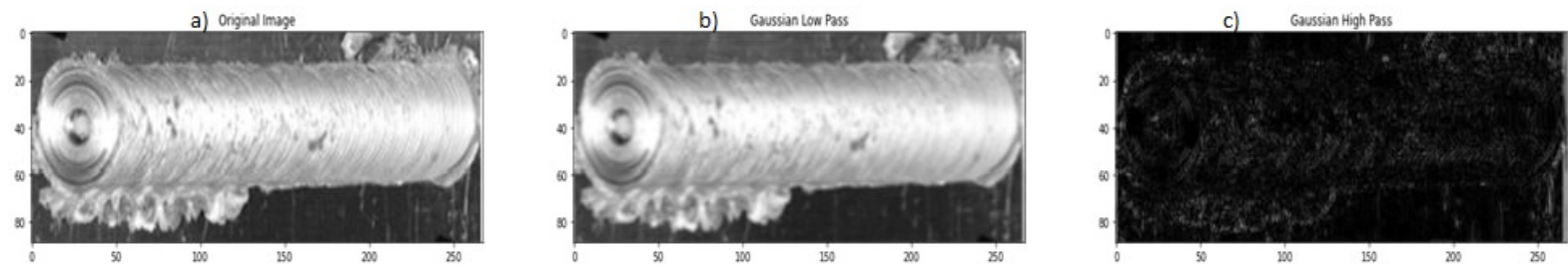

Figure 22. Edge detection by using High pass filter

\section{Conclusions}

In this paper, Local Binary Pattern algorithm and Fourier Transformation algorithm are proposed for evaluating the surface quality of Friction Stir Welded joints. Local Binary Pattern algorithm easily validated the detection of surface defects like lack of contact and flash formation in Friction Stir Welded joints. It is observed that when 6061-T6 is on retreating side then the LBP converted image shows more non-homogenous nature in comparison to arrangement when 6061-T6 is on advancing side also the former arrangement shows less peak values in histograms. So, it can be concluded that Local Binary Pattern (LBP) algorithm can be successfully implemented in visual inspection and in real-time monitoring. The research study also proposes a novel approach for surface edge detection in the Friction Stir Welded joint by using computer vision technique. It is observed that the Gaussian filter performs better than the Ideal filter and Butterworth filter because it results less distortion and more smoothness to the processed image. Also it is observed that the high pass filter has better advantage over other filters in terms of detecting surface edges. In the future research, Fourier transformation can play a vital role for image processing task by providing more flexibility.

\section{References}

[1] Jain R, Kasturi R, Schunck BG. Machine vision. Vol. 5. New York: McGraw-Hill; 1995. p. 309-364.

[2] Davies ER. Machine vision: theory, algorithms, practicalities. London: Elsevier; 2004.

[3] Sonka M, Hlavac V, Boyle R. Image processing, analysis, and machine vision. Australia: Cengage Learning; 2014.

[4] Vernon D. Machine vision-automated visual inspection and robot vision. STIA. 1991;92:40499.

[5] Steger C, Ulrich M, Wiedemann C. Machine vision algorithms and applications. Berlin: John Wiley \& Sons; 2018.

[6] Wildes RP, Asmuth JC, Green GL, Hsu SC, Kolczynski RJ, Matey JR, et al. A machine-vision system for iris recognition. Machine Vision and Applications. 1996;9(1):1-8. http://dx.doi.org/10.1007/BF01246633. 
[7] Tsai R. A versatile camera calibration technique for high-accuracy 3D machine vision metrology using off-the-shelf TV cameras and lenses. IEEE Journal on Robotics and Automation. 1987;3(4):323-344. http://dx.doi.org/10.1109/JRA.1987.1087109.

[8] Martínez Sandoval E, Martínez Rosas ME, Martínez Sandoval JR, Miranda Velasco MM, Ávila HC. Machine vision systems: a tool for automatic color analysis in agriculture. In: Hussmann S, editor. Automation in agriculture: securing food supplies for future generations. London: IntechOpen; 2017.

[9] Mishra RS, Ma ZY. Friction stir welding and processing. Materials Science and Engineering R Reports. 2005;50(1-2):1-78. http://dx.doi.org/10.1016/j.mser.2005.07.001.

[10] Pratik HS, Vishvesh JB. Friction stir welding of aluminium alloys: an overview of experimental findings - process, variables, development and applications. Proceedings of the Institution of Mechanical Engineers, Part L. 2019;233(6):1191-1226.

[11] Ramona G, Jorge FS. Friction stir welding development of aluminium alloys for structural connections. Proceedings of the Romanian Academy Series A. 2013;14:64-71.

[12] Rai R, De A, Bhadeshia HKDH, DebRoy T. Review: friction stir welding tools. Science and Technology of Welding and Joining. 2011;16(4):325-342. http://dx.doi.org/10.1179/1362171811Y.0000000023.

[13] Mijajlović M. Investigation and development of analytical model for estimation of amount of heat generated during FSW [thesis]. Nis, Serbia: Faculty of Mechanical Engineering Nis, University of Nis; 2012.

[14] Mijajlović M, Milčic D. Analytical model for estimating the amount of heat generated during friction stir welding: application on plates made of aluminium alloy 2024 T351. In: Kovacevic R, editor. Welding processes. London: IntechOpen; 2012. http://dx.doi.org/10.5772/53563.

[15] Rudrapati R. Recent advances in joining of aluminum alloys by using friction stir welding. In: Akdogan A, Vanli AS, editors. Mass production processes. London: IntechOpen; 2019.

[16] Sun Y, Tsuji N, Fujii H. Microstructure and mechanical properties of dissimilar friction stir welding between ultrafine grained 1050 and 6061-t6 aluminum alloys. Metals. 2016;6(10):249. http://dx.doi.org/10.3390/met6100249.

[17] Cai Y, Xu G, Li A, Wang X. A novel improved local binary pattern and its application to the fault diagnosis of diesel engine. Shock and Vibration. 2020;2020:9830162. http://dx.doi.org/10.1155/2020/9830162.

[18] Rader C, Brenner N. A new principle for fast Fourier transformation. IEEE Transactions on Acoustics, Speech, and Signal Processing. 1976;24(3):264-266. http://dx.doi.org/10.1109/TASSP.1976.1162805. 